\title{
Comparison of clinical characteristics and 10-year survival rates of revision hip arthroplasties among revision time groups
}

\author{
Serda Duman ${ }^{1}$, İsmet Yalkın Çamurcu², Hanifi Uçpunar², Ahmet Sevencan³ ${ }^{3}$ Şuayip Akıncı ${ }^{4}$, \\ Vedat Şahin ${ }^{4}$
}

\author{
'Department of Orthopaedics and Traumatology, Selahaddin Eyyubi State Hospital, \\ Diyarbakır, Turkey \\ 2Department of Orthopaedics and Traumatology, Faculty of Medicine, Erzincan \\ University, Erzincan, Turkey \\ ${ }^{3}$ Department of Orthopaedics and Traumatology, Sanlıurfa Training and Research \\ Hospital, Şanlıurfa, Turkey \\ ${ }^{4}$ Department of Orthopaedics and Traumatology, Baltalimani Bone and Joint Diseases \\ Training and Research Hospital, İstanbul, Turkey
}

Submitted: 5 December 2018; Accepted: 9 March 2019;

Online publication: 8 October 2019

Arch Med Sci 2021; 17 (2): 382-389

DOI: https://doi.org/10.5114/aoms.2019.88563

Copyright $\odot 2019$ Termedia \& Banach

\begin{abstract}
Introduction: No significant regression has been reported in revision total hip arthroplasty (THA) rates despite substantial progress in implant technologies and surgical techniques. It is critical to investigate how patient demographics, THA indications, surgical techniques, types of implants, and other factors influence the frequency of early and late revision surgery. The main purpose of the present study was to evaluate the clinical characteristics and 10-year survival rates of revision hip arthroplasties among revision time groups.

Material and methods: The clinical data of 396 patients who underwent revision hip arthroplasty between 2005 and 2011 were evaluated in this multi-centre study. Patients were assigned to one of four revision time groups based on the interval between the index hip arthroplasty and the revision surgery $(<2,2-5,5-10$, and $>10$ years).

Results: There were significant differences among revision time groups in terms of aetiology for primary hip arthroplasty, indications for revision hip arthroplasty, and types of revision procedures. Patients with hip dysplasia more frequently received revision hip arthroplasty within 2 years in contrast to those with osteoarthritis. Revision hip arthroplasties due to periprosthetic infection and instability were conducted earlier compared to aseptic loosening. The overall 10-year survival rate of revision hip arthroplasty was $83.2 \%$, and it was highest for the very early revisions ( $<2$ years).

Conclusions: According to our results, early revision hip arthroplasty was found to be mostly dependent on surgery-related factors rather than demographic factors. On the other hand, we observed that survival rates of very early revision hip arthroplasties are higher than late revision hip arthroplasties.
\end{abstract}

Key words: hip dysplasia, periprosthetic infection, instability, aseptic loosening, revision.

\author{
Corresponding author: \\ Serda Duman MD \\ Department of Orthopaedics \\ and Traumatology \\ Selahaddin Eyyubi State \\ Hospital \\ Dr. Şeref İnalöz St, Yenişehir, \\ 21000 Diyarbakır, Turkey \\ Phone: +905327859563 \\ E-mail: serdaduman@yahoo. \\ com
}




\section{Introduction}

Total hip arthroplasty (THA) is well documented as an effective treatment for end-stage hip osteoarthritis. Over 280,000 THA surgeries are performed annually in the USA alone, and this number is increasing due to population aging [1-4]. It has been reported, however, that up to $15 \%$ of THA procedures eventually fail and require revision surgeries. In the US, the cost of these revision surgeries is estimated at nearly 1 billion dollars annually [5-8]. In addition to the economic burden, revision THA requires longer surgical times and hospital stays compared to the primary procedure, and it carries greater risks of complications and mortality $[9,10]$. Despite substantial progress in implant technologies and surgical techniques, no significant regression has been reported in revision surgery rates. It is possible that hip replacement surgeries for younger and more active patients as well as the longer lifespan have contributed to this lack of progress. Furthermore, elderly patients may avoid revision surgery due to these dangers, resulting in disability and reduced quality of life [11-14].

Identifying the reasons for THA failure will help in the development of better treatment regimens. To this end, it is critical to investigate how patient demographics, THA indications, surgical techniques, types and sizes of implants, and postoperative complications, among other factors, influence the frequency of revision surgery at various times after primary treatment. However, few studies have examined in detail the reasons for revision surgery associated with different postoperative periods. Therefore, the main purpose of the present study was to evaluate the demographics, clinical characteristics, and 10-year survival rates of revision hip arthroplasties among revision time groups based on the interval between the index hip arthroplasty and the revision surgery.

\section{Material and methods}

This multi-centre retrospective study was approved by the institutional Ethical Review Board. A total of 396 patients (272 female, 124 male) who underwent revision hip arthroplasty between January 1, 2005 and December 31, 2011 at four institutions (one university hospital, one training and research hospital, and two state hospitals) were included in this study. All participating centres in the study are referral centres in their region, and all surgeries were performed by high volume surgeons (senior surgeons least 5 years' experience) on the field of arthroplasty. Patients were identified using a prospectively collected computerised database at each centre. Patients undergoing a second or further revision and those with a history of malignancy were excluded.
The patients' age, sex, aetiology of the index primary hip arthroplasty, index hip arthroplasty procedure (total/hemiarthroplasty), and duration between primary hip arthroplasty and revision surgery were investigated through medical records. The aetiologies for primary hip arthroplasty included primary osteoarthritis, rheumatoid arthritis, hip fracture (femur neck, trochanteric), congenital dysplasia of the hip, avascular necrosis, epiphysiolysis or Perthes disease, and post-traumatic arthritis. The subjects were assigned to one of four revision time groups based on the interval between the index hip arthroplasty and the revision surgery ( $<2,2-5,5-10$, and $>10$ years).

The primary indication for revision hip arthroplasty was evaluated for each patient through our clinical records, radiographs, and operative reports. Revision indications were grouped as follows: osteolysis (stem, cup, or both), aseptic loosening (stem, cup, or both), infection, metallosis, periprosthetic fracture, instability, polyethylene bearing wear, mechanical failure of implants (fracture of stem, cup, liner, or head), coxalgia associated with acetabular erosion after hemiarthroplasty, and failed hip resurfacing arthroplasty. In addition, the types of implants and the surgical approaches used in the index primary hip arthroplasty were recorded for all patients. The type of revision hip surgery (total, femoral, acetabular, or insert exchange) was also recorded for each patient. The mean follow-up time was 45.8 months (range: 1 to 150 months).

\section{Ethics}

This study was performed after receiving approval from the institutional Ethical Review Board. Informed consent was obtained from all patients.

\section{Statistical analysis}

Continuous data are presented as means and standard deviations, and categorical data are given as frequencies and percentages. Statistical analysis was performed using SPSS 20.0 (SPSS Inc., IBM, NY, USA). Group means were compared by one-way ANOVA and frequencies by Pearson's $\chi^{2}$ test. The 10-year implant survival following revision surgery was estimated for each revision time group ( $<2,2-5,5-10$, and $>10$ years) by Kaplan-Meier analysis, and the four groups were compared by log-rank test. Only patients with a minimum follow-up of 10 years were analysed by survival analysis. The endpoint for survival was defined as osteolysis, aseptic loosening, instability, periprosthetic fracture, or infection at the latest follow-up. No sample size calculation was performed prior to study; however, a post-hoc power analysis was performed by GPower software to detect the statistical power of the study. 


\section{Results}

The demographic and clinical characteristics of the patients are presented in Table I. There were significant differences among the revision time groups in patient aetiology for primary hip arthroplasty, indications for revision hip arthroplasty, and types of revision procedures.

Table I. Comparison of demographics and clinical characteristics among revision time groups

\begin{tabular}{|c|c|c|c|c|c|c|}
\hline \multirow[t]{2}{*}{ Variable } & \multicolumn{4}{|c|}{$\begin{array}{l}\text { The duration between primary hip arthroplasty } \\
\text { and revision surgery }\end{array}$} & \multirow[t]{2}{*}{$\begin{array}{c}\text { Total } \\
(N=396)\end{array}$} & \multirow[t]{2}{*}{$P$-value } \\
\hline & $\begin{array}{c}<2 \text { years } \\
\text { (very early) } \\
(n=120)\end{array}$ & $\begin{array}{c}2-5 \text { years } \\
\text { (early) } \\
(n=94)\end{array}$ & $\begin{array}{c}\text { 5-10 years } \\
\text { (inter- } \\
\text { mediate) } \\
(n=98)\end{array}$ & $\begin{array}{c}10 \text { years } \\
\text { (late) } \\
(n=84)\end{array}$ & & \\
\hline Age [years] & $\begin{array}{c}64.2 \pm 13.7 \\
(29-89)\end{array}$ & $\begin{array}{l}65.0 \pm 13.2 \\
(36-91)\end{array}$ & $\begin{array}{c}68.3 \pm 13.9 \\
(34-88)\end{array}$ & $\begin{array}{l}67.1 \pm 13.1 \\
(37-86)\end{array}$ & $\begin{array}{l}65.9 \pm 13.6 \\
(29-91)\end{array}$ & $0.143^{*}$ \\
\hline Sex: & & & & & & $0.107^{* *}$ \\
\hline Female & $92(77 \%)$ & $61(65 \%)$ & $61(62 \%)$ & $58(69 \%)$ & $272(69 \%)$ & \\
\hline Male & $28(23 \%)$ & $33(35 \%)$ & $37(38 \%)$ & $26(31 \%)$ & $124(31 \%)$ & \\
\hline Aetiology for index hip arthroplasty: & & & & & & $<0.001^{* *}$ \\
\hline Primary osteoarthritis & $46(38 \%)$ & $39(42 \%)$ & $58(59 \%)$ & $52(62 \%)$ & $195(49 \%)$ & \\
\hline Hip fracture & $34(28 \%)$ & $31(33 \%)$ & $26(27 \%)$ & $22(26 \%)$ & $113(28 \%)$ & \\
\hline Hip dysplasia & $27(23 \%)$ & $12(13 \%)$ & $4(4 \%)$ & $5(6 \%)$ & $48(12 \%)$ & \\
\hline Rheumatoid arthritis & $6(5 \%)$ & $4(4 \%)$ & $8(8 \%)$ & $2(3 \%)$ & $20(5 \%)$ & \\
\hline Avascular necrosis of femoral head & $4(3 \%)$ & $7(7 \%)$ & $2(2 \%)$ & $1(1 \%)$ & $14(4 \%)$ & \\
\hline Epiphysiolysis - Perthes & $2(2 \%)$ & $1(1 \%)$ & $0(0 \%)$ & $1(1 \%)$ & $4(1 \%)$ & \\
\hline Post-traumatic arthritis & $1(1 \%)$ & $0(0 \%)$ & $0(0 \%)$ & $1(1 \%)$ & $2(1 \%)$ & \\
\hline Index arthroplasty procedure: & & & & & & $0.280^{\star *}$ \\
\hline Total & $88(73 \%)$ & $64(68 \%)$ & $76(78 \%)$ & $67(80 \%)$ & $295(75 \%)$ & \\
\hline Hemiarthroplasty & $32(27 \%)$ & $30(32 \%)$ & $22(22 \%)$ & $17(20 \%)$ & $101(25 \%)$ & \\
\hline Indication for revision hip arthroplasty: & & & & & & $<0.001^{* *}$ \\
\hline \multicolumn{7}{|l|}{ Aseptic loosening: } \\
\hline Acetabular component & $2(2 \%)$ & $4(4 \%)$ & $9(9 \%)$ & $6(7 \%)$ & $21(5 \%)$ & \\
\hline Femoral component & $10(8 \%)$ & $26(28 \%)$ & $31(33 \%)$ & $15(18 \%)$ & $82(21 \%)$ & \\
\hline Both & $7(6 \%)$ & $12(13 \%)$ & $14(14 \%)$ & $27(32 \%)$ & $60(15 \%)$ & \\
\hline Infection & $28(23 \%)$ & $23(25 \%)$ & $11(11 \%)$ & $5(6 \%)$ & $67(17 \%)$ & \\
\hline Instability & $46(38 \%)$ & $4(4 \%)$ & $7(7 \%)$ & $1(1 \%)$ & $58(15 \%)$ & \\
\hline Periprosthetic fracture & $11(9 \%)$ & $5(5 \%)$ & $4(4 \%)$ & $6(7 \%)$ & $26(7 \%)$ & \\
\hline Metallosis & $0(0 \%)$ & $7(8 \%)$ & $12(12 \%)$ & $0(0 \%)$ & $19(5 \%)$ & \\
\hline Acetabular erosion & $8(7 \%)$ & $2(2 \%)$ & $2(2 \%)$ & $6(7 \%)$ & $18(5 \%)$ & \\
\hline \multicolumn{7}{|l|}{ Osteolysis: } \\
\hline Acetabular component & $4(3 \%)$ & $1(1 \%)$ & $1(1 \%)$ & $0(0 \%)$ & $6(2 \%)$ & \\
\hline Femoral component & $1(1 \%)$ & $2(2 \%)$ & $0(0 \%)$ & $1(1 \%)$ & $4(1 \%)$ & \\
\hline Both & $1(1 \%)$ & $0(0 \%)$ & $0(0 \%)$ & $0(0 \%)$ & $1(0 \%)$ & \\
\hline Polyethylene bearing wear & $0(0 \%)$ & $5(5 \%)$ & $3(3 \%)$ & $12(15 \%)$ & $20(5 \%)$ & \\
\hline Mechanical failure of implants & $2(2 \%)$ & $3(3 \%)$ & $3(3 \%)$ & $5(6 \%)$ & $13(3 \%)$ & \\
\hline Failed hip resurfacing & $0(0 \%)$ & $0(0 \%)$ & $1(1 \%)$ & $0(0 \%)$ & $1(0 \%)$ & \\
\hline Type of revision hip arthroplasty: & & & & & & $0.031^{* *}$ \\
\hline Total & $92(77 \%)$ & $74(78 \%)$ & $77(79 \%)$ & 79 (95\%) & $322(81 \%)$ & \\
\hline Acetabular & $7(6 \%)$ & $6(6 \%)$ & $8(8 \%)$ & $2(2 \%)$ & $23(6 \%)$ & \\
\hline Femoral & $17(14 \%)$ & $7(8 \%)$ & $10(10 \%)$ & $1(1 \%)$ & 35 (9\%) & \\
\hline Insert exchange & $4(3 \%)$ & $7(8 \%)$ & $3(3 \%)$ & $2(2 \%)$ & $16(4 \%)$ & \\
\hline
\end{tabular}

${ }^{\star} P$-value according to one-way ANOVA test, ${ }^{* *} P$-value according to Pearson's $\chi^{2}$ test, Bold $p$-values indicate statistical significance. 
Table II. Comparison of index arthroplasty procedure data of patients among revision time groups

\begin{tabular}{|c|c|c|c|c|c|c|}
\hline \multirow[t]{2}{*}{ Variable } & \multicolumn{4}{|c|}{$\begin{array}{l}\text { The duration between primary hip arthroplasty } \\
\text { and revision surgery }\end{array}$} & \multirow[t]{2}{*}{$\begin{array}{c}\text { Total } \\
(N=396)\end{array}$} & \multirow[t]{2}{*}{$P$-value } \\
\hline & $\begin{array}{c}<2 \text { years } \\
\text { (very early) } \\
(n=120)\end{array}$ & $\begin{array}{c}2-5 \text { years } \\
\text { (early) } \\
(n=94)\end{array}$ & $\begin{array}{c}5-10 \text { years } \\
\quad \text { (inter- } \\
\text { mediate) } \\
(n=98)\end{array}$ & $\begin{array}{c}>10 \text { years } \\
\text { (late) } \\
(n=84)\end{array}$ & & \\
\hline Index acetabular component fixation: & & & & & & $<0.001^{*}$ \\
\hline Cemented & $4(3 \%)$ & $10(11 \%)$ & $16(16 \%)$ & $20(24 \%)$ & $50(13 \%)$ & \\
\hline Cementless & $84(70 \%)$ & $54(57 \%)$ & $60(61 \%)$ & $47(56 \%)$ & $245(62 \%)$ & \\
\hline None (hemiarthroplasty) & $32(27 \%)$ & $30(32 \%)$ & $22(23 \%)$ & $17(20 \%)$ & $101(25 \%)$ & \\
\hline Index femoral component fixation: & & & & & & $<0.001^{*}$ \\
\hline Cemented & $34(28 \%)$ & $43(46 \%)$ & $44(45 \%)$ & $57(68 \%)$ & $178(45 \%)$ & \\
\hline Cementless & $86(72 \%)$ & $51(54 \%)$ & $54(55 \%)$ & $27(32 \%)$ & $218(55 \%)$ & \\
\hline Index femoral component design: & & & & & & $0.593^{*}$ \\
\hline Conical & $65(54 \%)$ & $46(49 \%)$ & $63(64 \%)$ & $51(61 \%)$ & $225(57 \%)$ & \\
\hline Cylindrical & $48(40 \%)$ & $46(49 \%)$ & $33(34 \%)$ & $33(39 \%)$ & $160(40 \%)$ & \\
\hline Rectangular & $2(2 \%)$ & $0(0 \%)$ & $0(0 \%)$ & $0(0 \%)$ & $2(1 \%)$ & \\
\hline Resurface & $5(4 \%)$ & $2(2 \%)$ & $2(2 \%)$ & $0(0 \%)$ & $7(2 \%)$ & \\
\hline Index femoral head size [mm]: & & & & & & $0.063^{*}$ \\
\hline 28 & $29(24 \%)$ & $10(10 \%)$ & $28(29 \%)$ & $19(23 \%)$ & $86(22 \%)$ & \\
\hline 32 & $45(37 \%)$ & 45 (48\%) & $45(46 \%)$ & $35(42 \%)$ & $170(43 \%)$ & \\
\hline 36 & $14(12 \%)$ & $9(10 \%)$ & $3(3 \%)$ & $13(15 \%)$ & $39(10 \%)$ & \\
\hline Other (hemiarthroplasty) & $32(27 \%)$ & $30(32 \%)$ & $22(22 \%)$ & $17(20 \%)$ & $101(25 \%)$ & \\
\hline Index bearing surface: & & & & & & $0.864^{*}$ \\
\hline Metal on polyethylene & $78(65 \%)$ & $54(57 \%)$ & $68(69 \%)$ & $59(71 \%)$ & $259(65 \%)$ & \\
\hline Metal on metal & $9(7 \%)$ & $9(10 \%)$ & $8(8 \%)$ & $7(8 \%)$ & $28(8 \%)$ & \\
\hline Ceramic on ceramic & $1(1 \%)$ & $1(1 \%)$ & $0(0 \%)$ & $1(1 \%)$ & $3(1 \%)$ & \\
\hline None (hemiarthroplasty): & $32(27 \%)$ & $30(32 \%)$ & $22(23 \%)$ & $17(20 \%)$ & $101(25 \%)$ & \\
\hline Index surgical approach: & & & & & & $0.039^{*}$ \\
\hline Posterolateral & $75(62 \%)$ & $58(62 \%)$ & $74(76 \%)$ & $47(56 \%)$ & $254(64 \%)$ & \\
\hline Lateral & $9(8 \%)$ & $12(13 \%)$ & $3(3 \%)$ & $6(7 \%)$ & $30(8 \%)$ & \\
\hline Anterolateral & 36 (30\%) & $24(25 \%)$ & $21(21 \%)$ & $31(37 \%)$ & $112(28 \%)$ & \\
\hline
\end{tabular}

${ }^{\star} P$-value according to Pearson's $\chi^{2}$ test, Bold $p$-values indicate statistically significance.

Primary osteoarthritis, hip fracture, and hip dysplasia were the three most common aetiologies for the index hip arthroplasty procedure (accounting for $49 \%, 28 \%$, and $12 \%$ of the total patient population, respectively). Patients with primary osteoarthritis were more common in the intermediate (5-10 years) and late (> 10 years) revision time groups compared to the very early ( $<2$ years) and early (2-5 years) revision time groups. For patients who underwent primary arthroplasty for hip fracture, the frequencies of the revision hip ar- throplasties were similar among the revision time categories. On the other hand, patients with hip dysplasia more frequently received revision hip arthroplasty within 2 years compared to 2-5 years after the initial operation ( $23 \%$ vs. $13 \%$ ). Thus, hip dysplasia patients generally demonstrated earlier primary arthroplasty failure than osteoarthritis patients, while failure appeared to occur at any time post-surgery in hip fracture patients.

The three most common indications for revision hip arthroplasty were aseptic loosening 


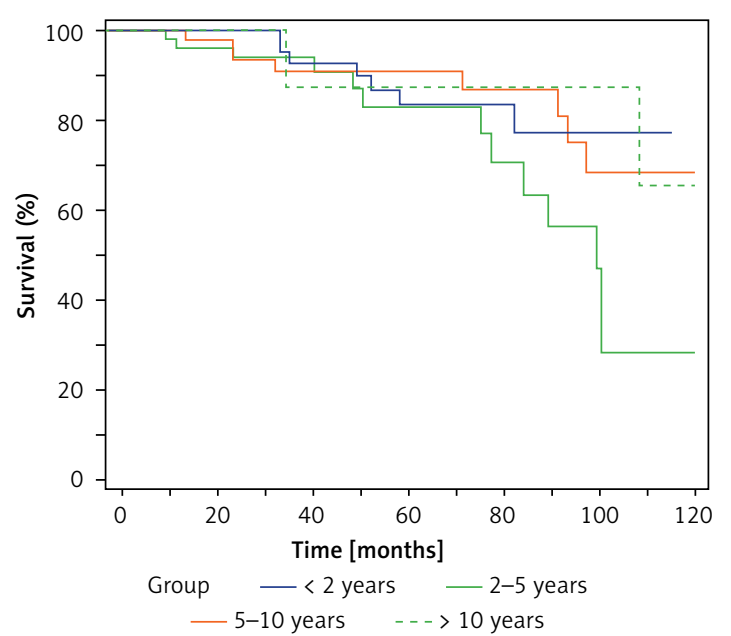

Figure 1. Line chart demonstrating 10-year survival of revision hip arthroplasties among revision time groups

(41\%), periprosthetic infection (17\%), and instability (15\%). Aseptic loosening was more frequent in the femoral component than in the acetabular component ( $21 \%$ vs. $5 \%$ ). Revision hip arthroplasty for aseptic loosening was more frequent in the 5-10 years and > 10 years revision time groups. On the other hand, revision hip arthroplasties due to periprosthetic infection were conducted most frequently within 5 years compared to later times, and revision surgeries for instability were conducted within $<2$ years.

The acetabular component fixation method, the femoral component fixation method, and the surgical exposure used for the index arthroplasty procedure also differed among the revision time groups. Cementless acetabular fixation was more common than cemented fixation among all primary hip arthroplasty patients (62\% vs. $13 \%$ ). However, the early revision hip arthroplasty rate was higher than the intermediate and late revision rates for cementless acetabular fixation. On the other hand, cementless and cemented femoral component fixations were employed at relatively similar rates for the index arthroplasty procedure (55\% and 45\%, respectively). For patients receiving cementless femoral fixation, the revision hip arthroplasty rate was higher in the first 2 years compared to the other revision times, while the rate of revision hip arthroplasty following cemented femoral fixation was higher at 2-5 years and 5-10 years ( $46 \%$ and $45 \%$, respectively). Revision hip arthroplasty was most common following index arthroplasty using the posterolateral hip approach $(64 \%)$, with the highest revision rate $5-$ 10 years after index surgery (Table II).

The overall 10-year survival rate of revision hip arthroplasty was $83.2 \%, 89.5 \%$ for the very early revisions ( $<2$ years), $78.6 \%$ for early revisions (2-5 years), $82.4 \%$ for the intermediate revisions
(5-10 years), and $84.2 \%$ for late revisions (> 10 years), without significant differences among the revision times $(p=0.204)$ (Figure 1 ).

\section{Discussion}

Revision THA surgery is more expensive, requires a longer surgical time and hospital stay, and has higher complication rates than primary surgery [15]. Due to higher incidence of complications (such as infection, venous thromboembolism, and dislocation) and higher mortality rate, orthopaedic surgeons are often wary to advise revision THA [16-21]. It has also been reported that revision surgery fails in up to $20 \%$ of the cases within the first 5 years, necessitating additional revision surgeries [22-24]. Nonetheless, revision surgery is increasing in frequency. It is therefore critical to identify the causes and factors that increase the risk among patient characteristics, primary surgical procedures, and implant types. Such information could help identify precautions to guide THA procedures and reduce risks of index and revision surgery failure. However, few studies have examined the causes of primary surgery failure necessitating revision surgery. Here we found that the aetiology influenced the time of THA failure, with generally earlier failure following THA for hip dysplasia than for osteoarthritis. Earlier failure was also associated with specific postoperative causes such as periprosthetic infection and instability. In addition, failure tended to occur earlier following cementless fixation than cemented fixation. However, earlier revision tended to be more successful over the long-term than later revision.

Studies examining the rates and causes of revision have generally been conducted on large samples from national databases $[1,2,4,5,10$, $14,15,25,26]$. However, such studies often omit critical demographic or clinical details in the analysis. Katz et al. also reported that many studies including a large number of patients could not identify long-term risk factors for revision due to insufficient follow-up time [25]. Additionally, these studies were mostly performed by reviewing ICD codes, which may be interpreted incorrectly due to incorrect data entry. As stated by Bozic et al., smaller sample sizes may be more meaningful in showing statistical changes [26]. For example, about this issue, although there is more common evidence that there is more aseptic loosening in the acetabulum than femur, some authors found that the rates are similar to each other. Unlike in the literature, we found significantly higher femoral aseptic loosening than acetabuler component.

Ulrich et al. also reported the detailed aetiology of primary arthroplasty and indications for revision THA according to revision time, as in our study [27]. In accordance with our study, osteoar- 
thritis was reported as the most common aetiology for primary THA in patients who underwent revision hip arthroplasty. In their study, osteoarthritis was the most common aetiology for all revision times except for very early THA revision ( $<2$ years) whereas osteonecrosis and post-traumatic arthritis were most common [25]. Ulrich et al. reported similar revision rates for all times among patients with hip dysplasia, while early revision was more common for hip dysplasia in our case series. In a study reporting the results of the Norwegian Arthroplasty Register, osteoarthritis, femur fracture, and hip dysplasia were the most common causes for both primary THA and revision, in general accord with our study [5]. The Norwegian Arthroplasty Register study also revealed an increased relative risk of revision THA after fracture of the femoral neck and congenital dislocation of the hip compared to primary osteoarthritis [5]. According to the results acquired from literature and our study, THA for hip dysplasia may be considered as particularly prone to early failure and revision THA compared to THA for osteoarthritis. This increased risk of early revision due to dislocation of THAs after hip dysplasia is commonly reported $[5,28]$. Total hip arthroplasty in hip dysplasia patients is often technically challenging, due to anatomical changes such as deficient bone stock in the acetabulum, increased acetabuler and femoral neck anteversion, valgus neck deformity, posteriorly located greater trochanter, narrow femoral canal, shortening, and rotational deformity, altered course of nerve, arteries, and muscles, or prior surgeries. Besides, special implants are needed, and procedures such as shortening of the femur and acetabular augmentation with bone grafting may be considered, which may prolong the operation times $[29,30]$.

Ulrich et al. reported that the most common cause for revision THA was aseptic loosening (51.9\%), and that infection and instability were the most common causes for very early revision ( $<2$ years after primary THA) [27], again in accord with our findings. Clohisy et al. also identified aseptic loosening as the most common cause of revision THA, accounting for $55 \%$ of all cases. In addition, these authors reported a conversion rate of $3 \%$ from hemiarthroplasty performed secondarily to trauma to total hip replacement [31]. Similarly to the current study, Haynes et al. found that aseptic loosening was the most common cause of revision but that early revision was more frequently due to instability and infection [32]. Dobzyniak et al. investigated the reasons for early revisions ( $<5$ years) in a cohort treated between 1986 and 2001 and found differences among treatment periods. While aseptic loosening was the most common cause of early revision between
1986 and 1991, instability and infection were predominant at later times, as in our study, probably reflecting improved implant technology [33]. Thus, our current study conducted on patients treated during and after 2005 yielded results generally consistent with previous studies. The most common reasons for very early revisions ( $<2$ years) were instability (38\%), infection (23\%), and aseptic loosening (16\%). Bozic et al. and Kamath et al. reviewed the epidemiology of revision THA in the USA and found instability/dislocation as the major cause of revision followed by mechanical loosening [34, 35]. Bozic et al. suggested that this could be explained by the high frequency of diagnosis codes unrelated to revision arthroplasty and that using the ICD-9-CM coding system could produce inaccurate results [34]. For example, there is more evidence that there is greater aseptic loosening in the acetabulum than in the femur, and some authors found that the rates are close to each other. Unlike in the literature, we found significantly higher femoral aseptic loosening than acetabuler component [6, 26, 32].

In our cohort, revisions of cementless acetabular components were performed most frequently in the first 2 years. Conversely, the number of revisions for cemented acetabular components increased over time and peaked after 10 years. A substantial difference was also found for femoral fixation, with a higher number of revisions within the first 2 years following cementless femoral fixation and greater numbers of revisions after 2 years in patients receiving cemented femoral fixation. Hailer et al. concluded that overlooked intraoperative fissures and fractures during the use of cementless femoral stems was a more frequent cause of failure than postoperative periprosthetic fractures due to minor trauma, especially within the first 2 years [36]. This notion was supported by Fernandez et al., who identified fractures during the use of cementless femoral stem [37]. Hailer et al. also reported that the rate of early revision following implantation of cementless acetabular components was high due to mechanical problems related to dislocation, and that the revision rate was the same for cemented acetabular components when the linear changes of cementless acetabular components in the late period were included [36]. Hooper et al. concluded that cementless THA had the lowest rate of aseptic loosening [38]. The authors also mentioned that cemented components had lower rates of revision in the short term, in agreement with our findings [38, 39].

Several studies have identified posterolateral incision as another factor influencing the risk of early revision following THA $[40,41]$. However, according to our results, the rate of intermediate revision (5-10 years) was higher than very 
early ( $<2$ years) and early ( $2-5$ years) revisions among patients treated using the posterolateral approach. Similarly, Maratt et al. reported that no surgical approach has a compelling advantage over any other, including for dislocation risk [42]. Ultimately, the surgical approach for primary THA should be chosen according to the surgeon preference and experience as well as the preference and anatomy of the patient [43].

The most important difference between the aforementioned studies and ours is that we also compared the 10-year survival of revision THA grouped according to revision time. According to our findings, the 10-year survival was higher in patients receiving very early revision ( $<2$ years) while no significant difference was observed among other revision time groups. The survival rate was lowest for patients who underwent revision hip arthroplasty 2 to 5 years after index arthroplasty. It can be explained by the highest rate of revision due to infection between 2 and 5 years after index arthroplasty. Patients who underwent revision arthroplasty due to infection may have poorer survival rates. When common surgeon-related factors contributing to very early revision such as dislocation are eliminated, prosthesis survival may be longer due to revising them with simpler solutions compared to aseptic loosening. As Ong et al. mentioned, the poorer survival of late revision surgery due to aseptic loosening or osteolysis could be explained by the more technically demanding procedure, the loss of bone stock, or the relatively long operative time during revision procedures [22].

Our study has several limitations. Firstly, the retrospective design does not permit conclusions on causality. However, the retrospective design of the study prevents patient selection bias. Secondly, the participating institutions are national referral centres that treat difficult cases. Thus, early revision may be more common than in the general THA population. Furthermore, the time between failure and surgery is not known precisely; therefore, some patients may have been categorised in the wrong revision time group. Nonetheless, this is the first study investigating differences in aetiological features, indications, implant fixation methods, implant types, and index surgery approaches among patient groups according to revision time. Through this analysis, we have identified several factors that appear predictive of early or later THA failure. Larger scale studies are warranted to verify these results. A post hoc analysis was performed for significant variables for the comparison of proportions. The minimum statistical power was calculated as 0.99 for the aetiology of the index arthroplasty, indication for revision hip arthroplasty, index femoral component, and index femoral component $(\alpha=0.05)$. However, the minimum statistical power was 0.29 for the type of the revision hip arthroplasty, and 0.34 for the index surgical approach $(\alpha=0.05)$.

In conclusion, according to our results, there were significant differences among revision time groups in terms of aetiology for primary hip arthroplasty and indications for revision hip arthroplasty. We observed that technically more demanding procedures such as hip dysplasia required earlier revision hip arthroplasty than primary osteoarthritis. Our results demonstrated that revision hip arthroplasties due to periprosthetic infection and instability were conducted earlier compared to aseptic loosening. On the other hand, we observed that survival rates of very early revision hip arthroplasties are higher than late revision hip arthroplasties.

\section{Conflict of interest}

The authors declare no conflict of interest.

\section{References}

1. Soderman P, Malchau H, Herberts P. Outcome after total hip arthroplasty: part I. General health evaluation in relation to definition of failure in the Swedish National Total Hip Arthoplasty Register. Acta Orthop Scand 2000; 71: 354-9.

2. Mahomed NN, Barrett JA, Katz JN, et al. Rates and outcomes of primary and revision total hip replacement in the United States medicare population. J Bone Joint Surg Am 2003; 85-A: 27-32.

3. Clohisy JC, Harris WH. The Harris-Galante porous-coated acetabular component with screw fixation. An average ten-year follow-up study. J Bone Joint Surg Am 1999; 81: 66-73.

4. Kurtz S, Mowat F, Ong K, Chan N, Lau E, Halpern M. Prevalence of primary and revision total hip and knee arthroplasty in the United States from 1990 through 2002. J Bone Joint Surg Am 2005; 87: 1487-97.

5. Furnes O, Lie SA, Espehaug B, Vollset SE, Engesaeter LB, Havelin LI. Hip disease and the prognosis of total hip replacements. A review of 53,698 primary total hip replacements reported to the Norwegian Arthroplasty Register 1987-99. J Bone Joint Surg Br 2001; 83: 579-86.

6. Bozic KJ, Kamath AF, Ong K, et al. Comparative epidemiology of revision arthroplasty: failed THA poses greater clinical and economic burdens than failed TKA. Clin Orthop Relat Res 2015; 473: 2131-8.

7. Kurtz SM, Ong KL, Schmier J, et al. Future clinical and economic impact of revision total hip and knee arthroplasty. J Bone Joint Surg Am 2007; 89 Suppl 3: 144-51.

8. Crowe JF, Sculco TP, Kahn B. Revision total hip arthroplasty: hospital cost and reimbursement analysis. Clin Orthop Relat Res 2003; 413: 175-82.

9. Eisler T, Svensson O, Tengström A, Elmstedt E. Patient expectation and satisfaction in revision total hip arthroplasty. J Arthroplasty 2002; 17: 457-62.

10. Gillam MH, Ryan P, Graves SE, Miller LN, de Steiger RN, Salter A. Competing risks survival analysis applied to data from the Australian Orthopaedic Association National Joint Replacement Registry. Acta Orthop 2010; 81: 548-55. 
11. Malchau H, Herberts P, Eisler T, Garellick G, Söderman P. The Swedish Total Hip Replacement Register. J Bone Joint Surg Am 2002; 84-A Suppl 2: 2-20. Erratum in: J Bone Joint Surg Am 2004; 86-A(2): 363.

12. Seyler TM, Mont MA, Ragland PS, Kachwala MM, Delanois RE. Sports activity after total hip and knee arthroplasty: specific recommendations concerning tennis. Sports Med 2006; 36: 571-83.

13. Meek RM, Allan DB, McPhillips G, Kerr L, Howie CR. Ep idemiology of dislocation after total hip arthroplasty. Clin Orthop Relat Res 2006; 447: 9-18.

14. Kurtz S, Mowat F, Ong K, Chan N, Lau E, Halpern M. Prevalence of primary and revision total hip and knee arthroplasty in the United States from 1990 through 2002. J Bone Joint Surg Am 2005; 87: 1487-97.

15. Bozic KJ, Katz P, Cisternas M, Ono L, Ries MD, Showstack J. Hospital resource utilization for primary and revision total hip arthroplasty. J Bone Joint Surg Am 2005; 87: 570-6.

16. Bozic KJ, Ries MD. The impact of infection after total hip arthroplasty on hospital and surgeon resource utilization. J Bone Joint Surg Am 2005; 87: 1746-51.

17. Jaffer AK, Barsoum WK, Krebs V, Hurbanek JG, Morra N, Brotman DJ. Duration of anesthesia and venous thromboembolism after hip and knee arthroplasty. Mayo Clin Proc 2005; 80: 732-8.

18. Khatod M, Barber T, Paxton E, Namba R, Fithian D. An analysis of the risk of hip dislocation with a contemporary total joint registry. Clin Orthop Relat Res 2006; 447: 19-23.

19. Pulido L, Parvizi J, Macgibeny M, et al. In hospital complications after total joint arthroplasty. J Arthroplasty 2008; 23 (6 Suppl 1): 139-45.

20. Lübbeke A, Katz JN, Perneger TV, Hoffmeyer P. Primary and revision hip arthroplasty: 5-year outcomes and influence of age and comorbidity. J Rheumatol 2007; 34: 394-400.

21. Patil S, Garbuz DS, Greidanus NV, Masri BA, Duncan CP. Quality of life outcomes in revision vs primary total hip arthroplasty: a prospective cohort study. J Arthroplasty 2008; 23: 550-3.

22. Ong KL, Lau E, Suggs J, Kurtz SM, Manley MT. Risk of subsequent revision after primary and revision total joint arthroplasty. Clin Orthop Relat Res 2010; 468: 3070-6.

23. Sierra RJ, Cooney WP $4^{\text {th }}$, Pagnano MW, Trousdale RT, Rand JA. Reoperations after 3200 revision TKAs: rates, etiology, and lessons learned. Clin Orthop Relat Res 2004; 425: 200-6.

24. Springer BD, Fehring TK, Griffin WL, Odum SM, Masonis JL. Why revision total hip arthroplasty fails. Clin Orthop Relat Res 2009; 467: 166-73.

25. Katz JN, Wright EA, Wright J, et al. Twelve-year risk of revision after primary total hip replacement in the U.S. Medicare population. J Bone Joint Surg Am 2012; 94: 1825-32.

26. Bozic KJ, Kurtz SM, Lau E, Ong K, Vail TP, Berry DJ. The epidemiology of revision total hip arthroplasty in the United States. J Bone Joint Surg Am 2009; 91: 128-33.

27. Ulrich SD, Seyler TM, Bennett D, et al. Total hip arthroplasties: what are the reasons for revision? Int Orthop 2008; 32: 597-604.

28. Colo E, Rijnen WHC, Gardeniers WM, Kampen AV, Schreurs BW. Satisfying results of primary hip arthroplasty in patients with hip dysplasia at a mean follow-up of 20 years. Clin Orthop Relat Res 2016; 474: 2462-8.

29. Greber E, Pelt CE, Gililland J, Anderson MB, Erickson J, Peters CL. Challenges in total hip arthroplasty in the setting of developmental dysplasia of the hip. J Arthroplasty $2017 ; 32: 38-44$.
30. Boyle MJ, Frampton CM, Crawford HA. Early results of total hip arthroplasty in patients with developmental dysplasia of the hip compared with patients with osteoarthritis. J Arthroplasty 2012; 27: 386-90.

31. Clohisy JC, Calvert G, Tull F, McDonald D, Maloney WJ. Reasons for revision hip surgery: a retrospective review. Clin Orthop Relat Res 2004; 429: 188-92.

32. Haynes JA, Stambough JB, Sassoon AA, Johnson SR, Clohisy JC, Nunley RM. Contemporary surgical indications and referral trends in revision total hip arthroplasty: a 10-year review. J Arthroplasty 2016; 31: 622-5.

33. Dobzyniak M, Fehring TK, Odum S. Early failure in total hip arthroplasty. Clin Orthop Relat Res 2006; 447: 76-8.

34. Bozic KJ. CMS changes ICD-9 and DRG codes for revision TJA. http://www2.aaos.org/aaos/archives/bulletin/ jun05/ fline1.asp (accessed: 5 May 2009)

35. Kamath AF, Ong KL, Lau E, et al. Quantifying the burden of revision total joint arthroplasty for periprosthetic infection. J Arthroplasty 2015; 30: 1492-7.

36. Hailer NP, Garellick G, Kärrholm J. Uncemented and cemented primary total hip arthroplasty in the Swedish Hip Arthroplasty Register. Acta Orthop 2010; 81: 34-41.

37. Fernandez FR, Garcia-Elias E, Gil-Garay E. Peroperative fractures in uncemented total hip arthroplasty: results with a single design of stem implant. Int Orthop 2008; 32: 307-13.

38. Hooper GJ, Rothwell AG, Stringer M, Frampton C. Revision following cemented and uncemented primary total hip replacement: a seven-year analysis from the New Zealand Joint Registry. J Bone Joint Surg Br 2009; 91: 451-8.

39. Kusserow A, Ficklscherer A, Kreuz PC, et al. Importance of a distal centralizer in experimental malpositioning of cemented stems. A biomechanical study on human femora. Arch Med Sci 2015; 11: 1324-9.

40. Ponzio DY, Poultsides LA, Salvatore A, Lee YY, Memtsoudis SG, Alexiades MM. In-hospital morbidity and postoperative revisions after direct anterior vs posterior total hip arthroplasty. J Arthroplasty 2018; 33: 1421-5.e1.

41. Arthursson AJ, Furnes O, Espehaug B, Havelin LI, Söreide JA. Prosthesis survival after total hip arthroplasty-does surgical approach matter? Analysis of 19,304 Charnley and 6,002 Exeter primary total hip arthroplasties reported to the Norwegian Arthroplasty Register. Acta Orthop 2007; 78: 719-29.

42. Maratt JD, Gagnier JJ, Butler PD, Hallstrom BR, Urquhart AG, Roberts KC. No difference in dislocation seen in anterior vs posterior approach total hip arthroplasty. J Arthroplasty 2016; 31 (9 Suppl): 127-3.

43. Miller LE, Gondusky JS, Bhattacharyya S, Kamath AF, Boettner F, Wright J. Does surgical approach affect outcomes in total hip arthroplasty through 90 days of follow-up? A systematic review with meta-analysis. J Arthroplasty 2018; 33: 1296-302. 